\title{
SYNERGISM AMONG SOME INSECTICIDES AND ERGOSTEROL BIOSYNTHESIS INHIBITING FUNGICIDES AGAINST PECTINOPHORA GOSSYPIELLA (SAUND.)
}

\author{
EL-REFAI, A. M. ${ }^{1}$, A. E. ABDEL-MONEAM ${ }^{1}$, H. A. MOHAMED ${ }^{1}$, S. A. MUSTAFA ${ }^{2}$ \\ AND H. F.M. ABDEL- HAMID ${ }^{2}$ \\ 1. Faculty of Agriculture, EL-azhar University, Cairo \\ 2. Plant Protection Research Institute, ARC, Dokki, Giza
}

(Manuscript received 7 July 2009)

\begin{abstract}
The toxicity of organophosphorus insecticide chlorpyrifos, pyrethroid insecticide cypermethrin, insect growth regulators, chlorfluazuron and biocide as a natural products spinosad increased when mixed with the ergosterol biosynthesis inhibiting (EBI) fungicides to newly hatched larvae of Pectinophora gossypiella. This study was carried out by feeding newly hatched larvae on artificial diet treated with different concentrations of the tested compounds either alone or in mixtures with EBI fungicide or IGR. Interestingly, these fungicides did not kill the larvae up to $100 \mathrm{ppm}$, moreover $20 \mathrm{ppm}$ of each EBI fungicide with concentrations of the insecticides increased the toxicity of these insecticides. Also, all data indicated that the calculated $\mathrm{LC}_{50}$ of the insecticides alone were higher than the insecticides and fungicides or IGR. For instance, chlorpyrephos at $6.25 \mathrm{ppm}$ caused $90.0 \%$ larval mortality and $100.0 \%$ larval mortality when mixed with $20 \mathrm{ppm}$ of each fungicides or $3 \mathrm{ppm}$ when mixed with IGR. The $\mathrm{LC}_{50}$ of chlorpyrifos alone were higher than that of chlorpyrifos when mixed with EBI fungicides and chlorfluazuron as IGR. For example, chlorpyrifos had $\mathrm{LC}_{50}$ equal $2.89 \mathrm{ppm}$, but $0.88,0.48,0.26,0.26$, and $0.13 \mathrm{ppm}$ when mixed with difenoconazol, tetraconazol, imazalil, fenarimol and chlorfluazuron respectively. Also, the insecticidal action increased by $3.2,6.02,14.45,11.11,22.23$ folds when mixed with the latter fungicides or the insect growth regulators. Cypermethrin at 25 and $12.5 \mathrm{ppm}$ resulted in 81.66 and $78.33 \%$ larval mortality when used alone, while these concentrations caused $100.0 \%$ larval mortality when $20 \mathrm{ppm}$ of each fungicide or $3 \mathrm{ppm}$ of IGR added to these concentrations. The $\mathrm{LC}_{50}$ values decreased when cypermethrin mixed with EBI fungicides or IGR, the $\mathrm{LC}_{50}$ were 1.95 , $0.85,1.01,0.65$ and $1.5 \mathrm{ppm}$ when mixed with difenoconazol, tetraconazol, imazalil, fenarimol and chlorfluazuron compared with $3.01 \mathrm{ppm}$ when cypermethrin used alone. Also, the insecticidal action increased by $1.54,3.45,2.98,4.63$, and 2.01 folds when mixed with the mentioned fungicides or the IGR respectively. Chlorfluazuron at $6.5 \mathrm{ppm}$ caused $86.66 \%$ larval mortality after 72 hr post treatment but the same concentration caused $100 \%$ larval mortality after $48 \mathrm{hr}$ from treatments when mixed with the latter EBI fungicides. $\mathrm{LC}_{50}$ values were $0.61,0.11,0.36$ and $0.29 \mathrm{ppm}$ respectively, compared with $1.01 \mathrm{ppm}$ when used alone, insecticidal action increased by $6.01,9.18,2.85$ and 3.48 folds respectively. Spinosad at $7.5 \mathrm{ppm}$ caused $85.0 \%$ larval mortality but the same concentration induced $100.0 \%$ larval mortality when mixed with imazalil and fenarimol as EBI fungicides or chlorfluazuron as IGR and caused 95.08 and 98.33 when mixed
\end{abstract}


with both difenoconazol and tetraconazol as EBI fungicides. $\mathrm{LC}_{50}$ values were decreased to $0.51,0.41,0.76,0.61$ and $0.56 \mathrm{ppm}$ when was mixed with difenoconazol, tetraconazol, imazalil, fenarimol and chlorfluazuron respectively, compared with $1.54 \mathrm{ppm}$ when used alone, insecticidal action was increased by $3.08,3.21$, $1.97,2.56$, and 2.75 folds respectively. These results suggested that EBI fungicides and the IGRs enhanced the insecticidal activity of chlorpyrifos, cypermethrin and spinosad against the pink bollworm $P$. gossypiella.

\section{INTRODUCTION}

Cotton growers in Egypt have experienced severe economic losses from cotton pests due to reduced yield, low lint quality and increased costs of insecticides ( Amin and Gergis 2006). Insect- pests are considered one of the important factors that influence cotton production and cause economical damage to the crop yield. Pink bollworm Pectinophora gossypiella (Saund) and the spiny bollworm Earias insulana (Boisd) are the most serious cotton pests in Egypt (Hussein et al._(002). They caused annually the greatest yield losses from the cultivated area.(Haque1991;.ElNaggar1998). Ergosterol biosynthesis inhibiting EBI fungicides is widely used in controlling pathogenic fungus. This group of fungicides inhibits fungi by blocking the cytochrome P-450 dependent demethylation at the C-14 position and thus inhibiting biosynthesis of the principal fungal sterol ergosterol (Ragsdal and Sislar 1991). These group of fungicides have been identified as potent synergists of pyrethroid insecticides in the honey bee. (Colin and Belzunces 1992). For example, 9-16 folds enhanced toxicity was recorded for the pyrethroid insecticides lambadacyalothrin when combined with the EBI fungicides prochloraz and propiconazol respectively, (Pilling and Jepson 1994). The mechanism of this synergism has been studied by (Plling et al.1995) reported that prochloraz delayed the metabolism, detoxication, excretion of lambadacyalothrin by inhibiting microsomal oxidation, effectively enhancing the toxicity of pyrethroids to the honey bee. Schmuck et al. (2003) found that slight synergistic effect of the thiacloprid to cyprodinil fungicide was observed with honey bee while a significant enhancement was found with EBI fungicides prochloraz and tebuconazol. The insect growth regulator is acting as chitin synthesis inhibitor in insects which confers a remarkable specification with low toxicity to mammals, birds and fish (Flint and Smith 1977). Also, the mixtures between these compounds and traditional insecticides increase the efficiency of these insecticides (Abdel-Sattar and EL-Guindy1988). Also, Raslan (2003) found that all mixtures of $25 \mathrm{ml}$ Spinosad with Consult, Atabron and Dursban at their half- recommended rates per feddan resulted in increasing their activity against the $3^{\text {rd }}$ instars larvae of cotton leaf worm $S$. littoralis. Also, Helalia et al (2006) found that the toxicity of the biocides was greatly enhanced 
when used at low rates of conventional insecticides such as pyrethroids and some organophosphorus compounds in combination with $B$. thuringiensis proved to be suitable to control the cotton leafworm Spodoptera littoralis. Abd-EL-Mageed et al (2006), reported that spinosad gave moderately initial and residual effect when tested alone whereas the most pronounced initial effect was achieved when spinosad was mixed with methoxyfenozide. Also, they reported that the highest residual activity was noticed when spinosad was mixed with chlorpyrifos. Toru Arakawa (2008) found that Polyoxin AL a fungicide that inhibits chitin synthesis, showed a synergistic effect with benzoylphenylurea insect growth regulators in killing Spodoptera litura larvae.

Based on these studies, the present work was conducted to evaluate the synergism among some EBI fungicides, insect growth regulators and both organophosphorus, pyrethroids insecticides and one natural product spinosad against the pink bollworm P.gossypiella..

\section{MATERIALS AND METHODS}

\section{1-INSECTS}

Eggs of pink bollworm Pictinophora gossypiella (Saund.) were obtained from colony maintained in the laboratory of Bollworm Department Plant Protection Institute Agric. Res. Cent. These insects were not previously exposed to any insecticide. The newly hatched larvae were reared on artificial diet for maintaining mass cultures of the tested insects according to Abdel-Hafeze et al. (1982). The larvae were transferred to glass vials $(2 \times 7.5 \mathrm{~cm})$ containing $3 \mathrm{gm}$. artificial diet and incubated at $27^{\circ} \mathrm{C} \pm 1{ }^{\circ} \mathrm{C}$ and $80-85 \%$ R.H to obtain mass culture of insects and new egg for subsequent studies.

\section{2-CHEMICALS}

The following insecticides, fungicides were employed:-.

\section{1- INSECTICIDES}

1-1- Dursban (chlorpyrifos $48 \%$ E.C) as OP insecticide

1-2 -Polytrin (cypermethrin $20 \% \mathrm{E} . \mathrm{C}$ ) as pyrethroids insecticide

1-3-Atabron (chlorfluazuron $5 \%$ E.C) as insect growth regulator

1-4-Spintor (Spinosad $24 \%$ E.C) as natural product

\section{2 -FUNGICIDES}

2- 1- Score (difenoconazol, $25 \%$ E.C)

2 - 2 - Domark (tetraconazole, $12.5 \%$ E. C)

$2-3$ - Fungaflor (imazalil $70 \%$ E.C)

2 - 4 - Rubigan (fenarimol $12 \%$ E.C) 


\section{3-TOXICITY TESTS}

The toxicity of the insecticides applied separately or mixed with various fungicides and one insect growth regulators was tested on the newly hatched larvae of Pectinophpra gossypiella. This test was carried out using artificial diet to determine the $\mathrm{LC}_{50}$ values of the tested compounds alone or in mixtures with both fungicide or insect growth regulator. Serial concentrations with water of the test compound in water were prepared $6.25,3.12,1.56,0.78,0.39,0.195$ and $0.09 \mathrm{ppm}$ for chlorpyrifos and $25,12.5,6.25,3.12,1.56,0.78,0.39$, for cyprmethrin and $6.50,3.25,1.62,0.812$, $0.406,0.2030 .101 \mathrm{ppm}$ for chlorfluazuron and 7.5, 3.75,1.87, 0.93,0.46, 0.23, 0.11 ppm for spinosad used alone or in mixtures with $20 \mathrm{ppm}$ of fungicides or $3 \mathrm{ppm}$ of insect growth regulator added to the first concentration then diluted gradually until seven concentrations. The diet was put into glass tubes $(2 x 7.5 \mathrm{~cm})$ approximately $3 \mathrm{~g}$. diet / tube. Three replicates being used per concentration, each containing 20 glass tube. Tubes containing diet were treated with $0.05 \mathrm{ml}$ of each concentration from each compounds. For the check treatments the diet was treated with $0.05 \mathrm{ml}$ distilled water. All tubes were exposed to air current for $30 \mathrm{~min}$ to insure absorption of the compound on the diet surface. Single newly hatched larva was transferred carefully to each tube using fine hair brush, and the tubes were plugged with cotton and kept at $27^{\circ} \mathrm{C} \pm 1^{\circ} \mathrm{C}$ and $80-85 \%$ R.H. Inspection of larval mortality was recorded $24 \mathrm{hrs}$ after chlorpyrifos, pyrethroids and spinosad treatment, but chlorfluazuron treatment alone was recorded at 72 hrs or where in mixtures with fungicides or insecticides was recorded at $48 \mathrm{hrs}$. Corrected mortality percent was obtained using check treatment and Abbott's formula Abbott's (1925). Calculation of LC 50 values were subjected to probit analysis Finney (1971) and were expressed as concentration that gives $50 \%$ mortality. The synergistic action calculated according to Sun and Johnson (1960) as following:

$$
\begin{gathered}
\text { synergistic ratio }=\frac{\mathrm{LC}_{50} \text { of the insecticides alone }}{\text { mixture of the insecticides } \mathrm{LC}_{50}} \\
\text { RESULTS AND DiSCUSSION }
\end{gathered}
$$

\section{RESULTS AND DiSCUSSION}

Results in Table (1) show the, toxicity and synergistic action of the tested compound used alone or in mixtures with EBI fungicides or IGR at different concentrations to the newly hatched larvae of $P$. gossypiella. The present data proved that $\mathrm{LC}_{50}$ of chlorpyrifos, cypermethrin, chlorfluazuron and spinosad were 2.89, 3.01, 1.01 and $1.54 \mathrm{ppm}$ when used alone respectively. Data in the same table indicate that the $\mathrm{LC}_{50}$ values, were decreased when these compounds were mixed with EBI 
fungicides or IGR. The $\mathrm{LC}_{50}$ values were $0.88,0.48,0.26,0.26$ and $0.13 \mathrm{ppm}$ when chlorpyrifos was combined with difenoconazol, tetraconazole, imazalil, fenarimol as EBI fungicide and chlorfluazuron as IGR respectively, compared with $2.89 \mathrm{ppm}$ when used alone. This indicate that insecticidal action increased by $3.2,6.02,14.45,11.11$ and 22.23 folds respectively. Also these values decreased when cypermethrin was mixed with both EBI fungicides and IGR. These values were 1.95,0.85, 1.01, 0.65 and $1.5 \mathrm{ppm}$ respectively, compared with $3.01 \mathrm{ppm}$ when cypermethrin was used alone. The insecticidal action increased by $1.54,3.54,2.98,4.63$ and 2.01 folds respectively. These values were decreased when chlorfluazuron was combined with EBI fungicides however these values were $0.61,0.11,0.36$ and $0.29 \mathrm{ppm}$ when mixed with difenoconazol, tetraconazol, imazalil, fenarimol respectively, compared with $1.01 \mathrm{ppm}$ when this compound was used alone. The toxicity of this compound increased by $6.01,9.18,2.85$ and 3.48 folds respectively. Also the same data indicated that the decrease in the $\mathrm{LC}_{50}$ values were obtained when the spinosad was mixed with EBI) fungicides or IGR and these values were $0.51,0.41,0.78,0.61$ and $0.56 \mathrm{ppm}$ when mixed with difenoconazol, tetraconazol, imazalil, fenarimol and the IGRs chlorfluazuron respectively, compared with $1.54 \mathrm{ppm}$ for Spinosad when used alone. The insecticidal action increased by $3.08,3.21,1.97,2.56$ and 2.75 folds respectively. Mixtures of EBI fungicides or IGR with different concentrations of organophosphorus insecticides (Chlorpyrifos) or pyrethroids insecticides (Cypermethrin) or natural product (Spinosad) enhanced the toxicity of these insecticides. Interestingly, the fungicides at different concentrations did not cause larval ortality.

\section{Chlorpyrifos toxicity}

The results in Table (2) indicate that chlorpyrifos alone at $0.09 \mathrm{ppm}$ did not cause any mortality but by increasing the concentration of this compound the larval mortality was increased. Chlorpyrifos at $0.195 \mathrm{ppm}$ caused $3.33 \%$ mortality but at $0.39 \mathrm{ppm}$ caused $5 \%$ larval mortality, moreover $68.33 \%$ larval mortality was achieved when the larvae were fed on artificial diet treated with $3.12 \mathrm{ppm}$. The insecticides caused $90 \%$ larval mortality when the artificial diet were treated with $6.25 \mathrm{ppm}$. Mortality assessment $24 \mathrm{hrs}$ post treatment of co-application of chlorpyrifos with EBI fungicides or IGR, revealed increasing insecticides toxicity for these treatments as well as chlorpyrifos-IGR mixtures. Chlorpyrifos at $0.09 \mathrm{ppm}$ did not cause any mortality to larvae as mentioned above while this concentration caused $36.66,31.66,36.66,35.59$ and $41.66 \%$ larval mortality when it was mixed with difenoconazol, tetraconazol, imazalil, fenarimol, and the IGR(chlorfluazuron0), respectively. Also, chlorpyrifos alone at $0.39 \mathrm{ppm}$ caused $5 \%$ larval mortality while this concentration induced $49.15,48.33,61.66,66.10$ and $78.33 \%$ larval mortality 
when mixed with difenoconazol, tetraconazol, imazalil, fenarimol, as EBI fungicides and chlorfluazuron as IGR, respectively. These results showed that chlorpyrifos at 3.12 ppm caused $68.33 \%$ larval mortality when used alone however, this concentration caused $93.22,81.66,95.55,89.83$ and $100 \%$ larval mortality when was mixed with difenoconazol, tetraconazol, imazalil, fenarimol, as EBI fungicides and chlorfluazuron as IGR respectively. Interestingly, chlorpyrifos at $6.25 \mathrm{ppm}$ when used alone resulted in $90 \%$ larval mortality, but when was mixed with both EBI fungicides or IGR caused $100 \%$ larval mortality.

\section{Toxicity of cypermethrin}

Toxicity of cypermethrin to the newly hatched larvae of $P$. gossypiella shown in Table (3) indicate that the lowest concentrations $0.39 \mathrm{ppm}$, caused $13.33 \%$ larval mortality but, increasing the concentration resulted in great increment of cypermethrin toxicity. Cypermethrin at high concentration 25 ppm caused $81.66 \%$ larval mortality when used alone. Concerning cypermethrin-EBI fungicides or IGR mixtures shown in this table clearly indicate that the cypermethrin toxicity to larvae increased by adding the fungicides or IGR. For example $0.78 \mathrm{ppm}$ of cypermethrin caused $16.66 \%$ larval mortality when used alone but cypermethrin-fungicides-IGR mixtures at the same concentration caused $43.11,49.15,39.65,50.84$, and $28.81 \%$ larval mortality when was mixed with difenoconazol, tetraconazol, imazalil, fenarimol, and the IGR respectively. All high concentrations such as $25,12.5$ ppm caused 81.66 and $78.33 \%$ larval mortality when were used alone, but when were mixed with EBI fungicides or insect growth regulator, caused $100 \%$ larval mortality. Generally both EBI fungicides or IGR greatly increased the insecticidal action of cypermethrin in all the tested concentrations.

\section{Toxicity of chlorfluazuron}

Data in Table (4) show the effect of chlorfluazuron alone or mixed with EBI fungicide on $P$. gossypiella larvae. The mortality percent of the newly hatched larvae P. gossypiella at higher concentration $(6.5 \mathrm{ppm})$ of chlorfluazuron alone was $86.66 \%$ after 72 hrs. These mortality percent increased to $100 \%$ after mixing with EBI after $48 \mathrm{hr}$. The low concentration (0.101 ppm) of chlorfluazuron alone caused $10.0 \%$ mortality after $72 \mathrm{hr}$ compared with 30.0, 48.33, 20.33 and $25.33 \%$ mortality after mixing with EBIs after $48 \mathrm{hr}$. These results clearly indicate that EBIs fungicide accelerated and increased the activity of chlorfluazuron against $P$. gossypiella larvae. The insect growth regulators is acting as chitin synthesis inhibitor in insects which confers a remarkable specification with low toxicity to mammals, birds and fish

\section{Toxicity of Spinosad}


Data in Table (5) indicate that spinosad at $0.11 \mathrm{ppm}$ caused $8.33 \%$ larval mortality but increasing the concentration gradually resulted in great increment of mortality. Spinosad at 1.87 and 3.75 ppm caused 53.3 and $75 \%$ larval mortality, however 7.5 ppm gave $85 \%$ larval mortality.

Concerning spinosad and EBI fungicide and IGR mixtures shown in the same table clearly indicate that the spinosad toxicity to larvae was increased by adding the fungicide or IGR to spinosad concentrations. For instance $0.11 \mathrm{ppm}$ of Spinosad caused $8.33 \%$ larval mortality, but the same concentration when mixed with EBI fungicides, i.e., difenoconazol, tetraconazol, imazalil, fenarimol, or IGR chlorfluazuron, caused $16.66,36.66,33.33,23.33$, and $43.3 \%$ larval mortality respectively. Indeed, spinosad alone at 1.87 and $3.75 \mathrm{ppm}$ caused 53.3 and $75 \%$ larval mortality but caused 78.33 and $91.66 \% 86.66$ and $93.33 \%$ larval mortality when these concentrations were mixed with, difenoconazol, and tetraconazol respectively. Interestingly, the spinosad alone at $7.5 \mathrm{ppm}$ induced $85 \%$ larval mortality, this concentration caused $100 \%$ larval mortality when was mixed with both imazalil, fenarimol as EBI fungicides and chlorfluazuron as IGR respectively. Also, the same concentration gave 98.33 and $95.08 \%$ larval mortality when was mixed with tetraconazol and difenoconazol, respectively as EBI fungicide.

\section{DISCUSSION}

Mixtures of EBI fungicides or IGR with different concentrations of organophosphorus insecticides (Chlorpyrifos) or pyrethroids insecticides (Cypermethrin) or natural product (Spinosad) enhanced the toxicity of these insecticides. Interestingly, the fungicides at different concentrations did not cause larval mortality. This effect was also reported by (Schmuck et al., 2003) and (Pilling et al.,1995). They found that the EBI fungicides did not have toxic effect to honey bee. It is known that these fungicides inhibit cytochrom P450 monooxygenase system which prevent the biosynthesis ergosterol in fungi. Since, monooxygenase are also involved in the metabolism of organophosphorus, and pyrethroid insecticides (Littele et al.,1989 and Johnston et a/ 1989).Thus fungicides may delay the toxification, of insecticides by inhibiting monooxygenase system in the insects, and enhanced their toxic action against larvae. Moreover, it has been reported that fungicides that did not inhibit the biosynthesis of ergosterol in fungi did not enhance the toxicity of thiacloprid to honey bee (Schmuck et al.,2003). These results also, agree with the previous studies (Colin and Belzunnces 1992). They reported that the fungicides have been identified as synergists of pyrethroids insecticides in the honey bee. (Plling and Jepson 1994). Found that the toxicity of pyrethroid were enhanced from 9-16 folds when combined 
with EBI fungicides Prochloraz and Propiconazol to honey bee. The insect growth regulators ar acting as chitin synthesis inhibitor in insects which confers a remarkable specification with low toxicity to mammals, birds and fish (Flint and Smith 1977). Also, the mixtures between these compounds (IGRs) and traditional insecticides increase the efficiency of these insecticides (Abdel-Sattar,1988). Also, (Raslan 2003) found that all mixtures of $25 \mathrm{ml}$ Spinosad with Consult, Atabron and Dursban at their halfrecommended rates per feddan resulted in increasing their activity against the $3^{\text {rd }}$ instars larvae of cotton leaf worm. Also, (Helalia et al. 2006) found that the toxicity of the biocides was greatly enhanced when using low rates of conventional insecticides such as pyrethroids and some organophosphorus compounds in combination with $B$. thuringiensis proved to be suitable to control the cotton leaf worm $S$. littoralis Abd-ELMageed et al (2006) reported that spinosad gave moderately initial and residual effect when tested alone whereas the most pronounced initial effect was achieved when spinosad was mixed with methoxyfenozide. Also, they reported that the highest residual activity was noticed when spinosad was mixed with chlorpyrifos. Toru Arakawa (2008) found that Polyoxin AL a fungicide that inhibits chitin synthesis, showed a synergistic effect with benzoylphenylurea insect growth regulators in killing Spodoptera litura larvae.

As mentioned before it could be used as mixtures of these fungicides or IGR with the insecticides to increase the insecticidal activity at low concentrations. 
1052 SYNERGISM AMONG SOME INSECTICIDES AND ERGOSTEROL BIOSYNTHESIS INHIBITING FUNGICIDES AGAINST PECTINOPHORA GOSSYPIELLA (SAUND.) 


\section{REFERENCES}

1. Abbot, W. S. 1925. A methods for computing the effectiveness of insecticides .J. Econ. Entomol., 18:256-257.

2. Abd El-Mageed, M. E. A., M. E. Anwar, A. R. L. Elgohary and H. F. Dahi. 2006. Field efficiency of novel biocide Spinosad singular, mixed with different groups of insecticides and compared with other biocide in sequence experiment on cotton leaf worm Spodoptera littorals. Bull.Ent. Soc. Egypt Ser(32) 91-99

3. Abdel-Sattar, M. M. and A. El-Guindy. 1988. Effect the juvenoid tripene on the biological activity of the pink bollworm P.gossypilla(saund.) Agric.Res. Rev., 66:1 19-23

4. Abdel-Hafez, A., A. G. Metwaly and M. R. A Soleh. 1982. Rearing pink bollworm (Saund) on kidney beans diet in Egypt Lepidoptera Gelchiidae. Res. Bull. Fac. Agric. Zagazig .University. 276.

5. Amin, A. A. and M. F. Gergis. 2006. Integrated management strategies for control of cotton key pests in middle Egypt. Agronomy . Research 4 121- 128.

6. Arakawa, Toru. 2008. Synergistic effect of a fungicide containing polyoxin B with insect growth regulators (IGRs) in the killing of common cutworm Spodoptera litura (Lepidoptera : Noctuidae). Applied Entomology and Zoology Vol. 43, pp. 167- 171.

7. Colin, M. E. and L. Belzunces. 1992. Evidence of synergism between prochloraz and deltamethrin in Apis melifera Biological approach. Pistic .Sci 36:115.

8. EL- Nagar, A. 1998. Evaluation of certain foliar and micro- elements in an Integrated Pest. Management (IPM) Program to control cotton boll worms. Msc.thesis. Fac. Of Agric. (Saba Bacha, Alexandria. Univ.Egypt. 176 pp.

9. Flint, H. M. and R. L. Smith.1977. Laboratory evaluation of TH 60- 40 against the pink bollworm. J.Eco. Ent., 70:51-53

10. Fnney, D. J. 1971. Probit Analysis ( $2^{\text {nd }} E D$.) CombridgeUniversity Press Landon.

11. Haque, H. 1991. Imported generic pesticides need to checked before marketing. Pakistan . Agric. Pesticides. Association Bulletin 616 -17

12. Helalia, A. R., S. A. Abou-Donia, O. K. Mustafa, N. S. Abdel-Hai. 2006. Effect of certain insecticides in enhancing the potency of Bacillus thuringinsis against the cotton leaf worm Spodoptera littoralis.Annals of Agricultural. Science. Cairo. 51 : (2) $573-5$.

13. Hussein, N. M., F. F. shalaby, E. F. EL-Khayat, S. M. Tawfik and M. S. Salem. 2002. Effect of certain organochemicals on cotton growth and bollworms 
infestation during three successeve seasons at kalubia governorate. Egipt $2^{\text {nd }}$ International conference, Plant. Protection. Research Institute. Cairo. Egypt 21-24 December, pp854-858

14. Johnston,G., G. Collet., C. Walker, I. Dawson and D. Osbom. 1989. Enhancement of malathion toxicity to the hybrid red legged partridge following exposure to prochloraz Pistic. Biochem.Physiol.35:107-11

15. Littele, J., A. R. McCaughey, C. H. Walker and T. Parker. 1989. Evidence for enhanced metabolism of Cypermethrin by a monooxygenase in pyrethroids resistant strain of the tubaco budworm (Heliothis veresens) Pest. Biochem. Bhysiol.34:58-68.

16. Pilling, E. D. and P.C. Jepson. 1994. Synergism between EBI fungicides and a pyrethroids fungicides and a pyrethroids insecticides in the honey bee (Aphis melifera Pestic .Sci.:39:294-297

17. Pilling, E. D., K. A. Bromly-challenor, C. Walker and P. C. Jepson. 1995. Mechanism of synergism between the pyrethroid insecticides lambadacyalothrin and imidazo fungicides prochloraz. Pistic.Biochem.Physiol 51: 1-11.

18. Ragsdale, N. N. and H. D. Sisler. 1991. Mode of action of fungicide in Chemistry, Biochemistry and Toxicology of Pestic Education Program Organ State University P41-45

19. Raslan, A. A. S. 2003. Comparison of natural product Spinosad with some recommended insecticides for the control of the cotton leaf worm at sharkia governorate Egypt. Egypt J. Appl.Sci 18(4B).

20. Schumuck, R., T. Stadler and H. W. Schmidt. 2003. Field relevance of a synergistic effect observed in the laboratory between EBI fungicides and chloronicotinyle insecticide in the honeybee(Aphis melifera). Pestic. Manag. Sci. 59: 279.

21. Sun, Y. P. and E. R. Johnson. 1960. Analysis of joint action of insecticides against house flies.J.Econ. Entomol., 53: 87-92 . 
الفعل التششيطي بين بعض المبيدات الحشرية والمبيدات الفطرية المثبطة لتخليق الايرجسترول في الفطريات ضد دودة اللوز القرنقلية

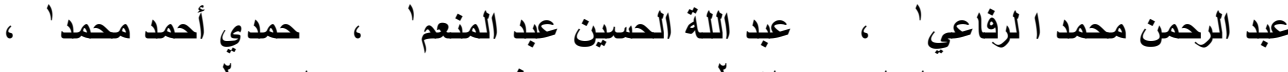

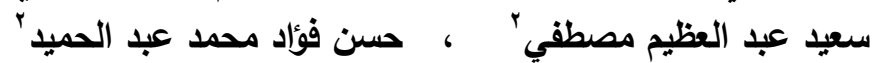

$$
\begin{aligned}
& \text { ا ـ ـلبة الزراعة - جامعة الأزهر - القاهزة } \\
& \text { r . معرد بحوث وقابة النباتات - مركز البحوث الزراعية - الدقي - الجيزة }
\end{aligned}
$$

في تجربة معملية نم تغذية الفقس الحديث لدودة اللوز القرنفلية علي بيئة غذائية صناعية معاملة

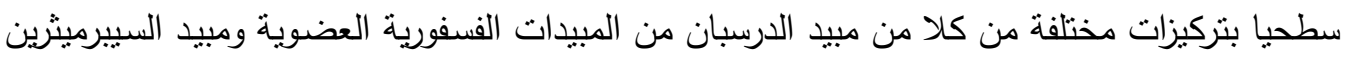

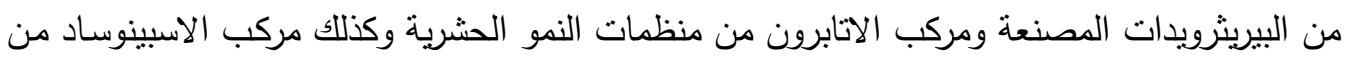

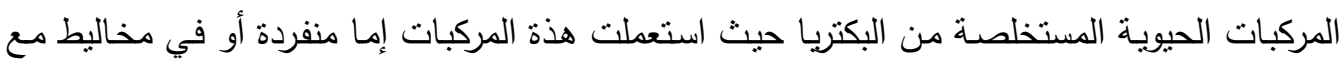

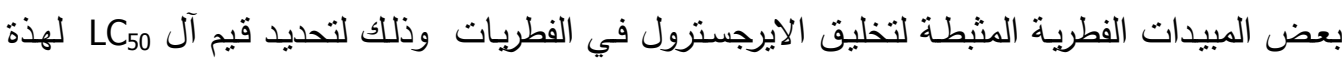

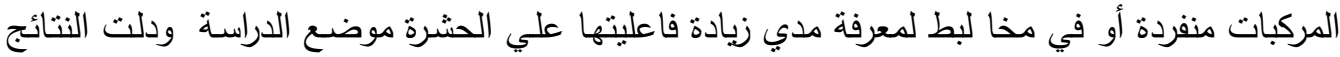

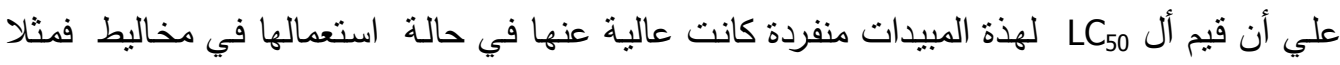

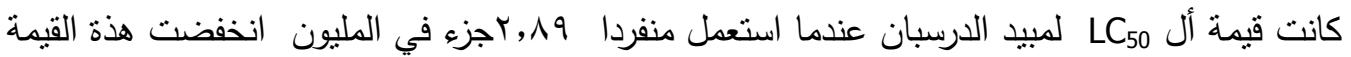

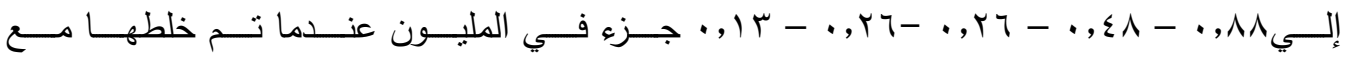
difenoconazol- tetraconazol- imazalil- fenarimol

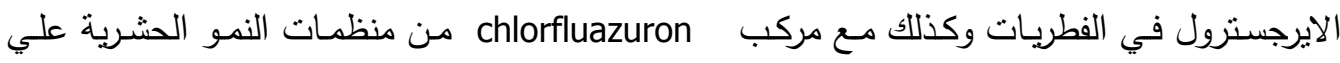

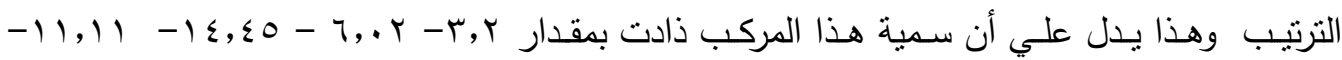

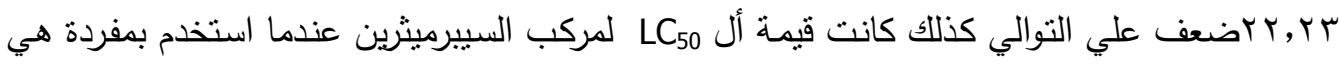

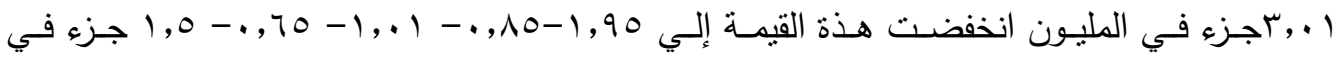

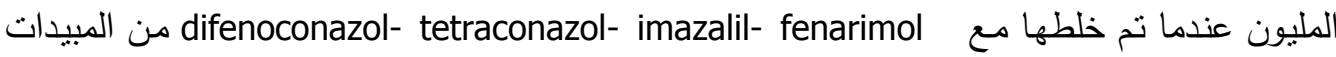
الفطرية المثبطة لتخليق الايرجسترول في الفطريات وكذلك مع مركب chlorfluazuron من منظمات

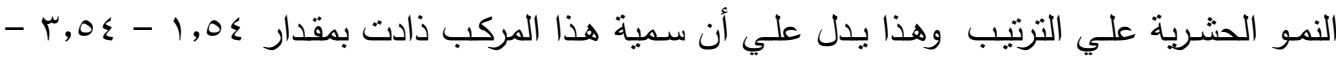

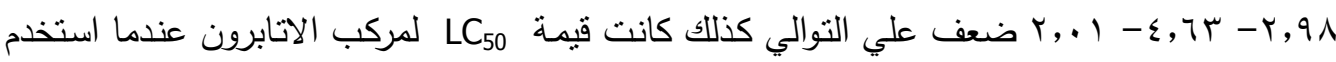

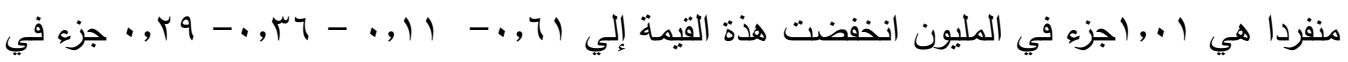

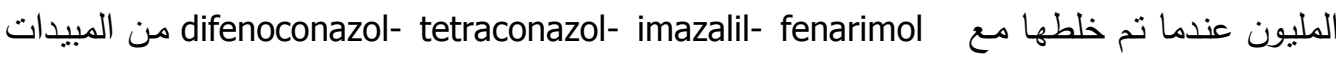

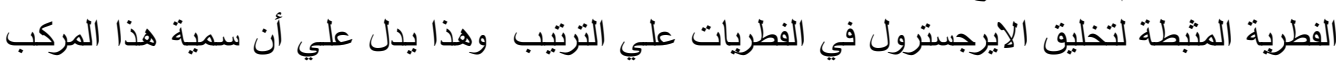

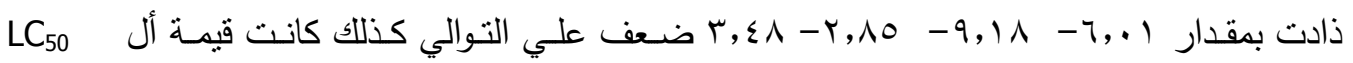

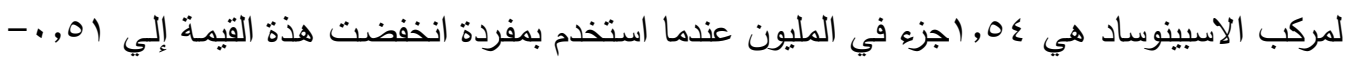

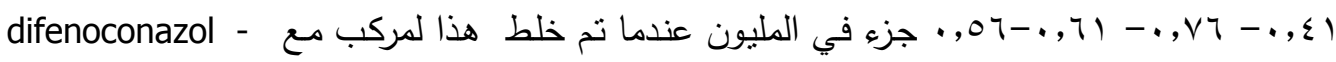
tetraconazol- imazalil- fenarimol

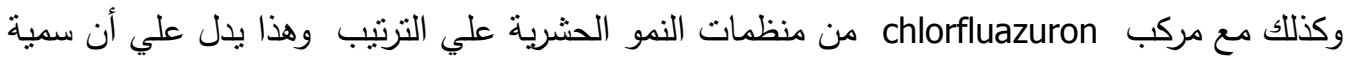

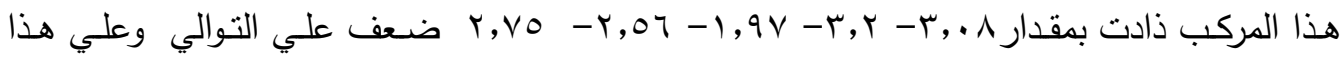

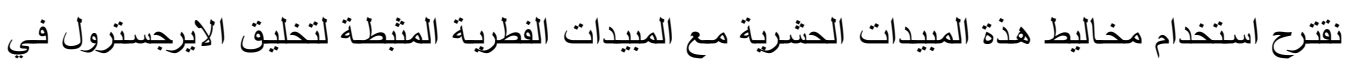

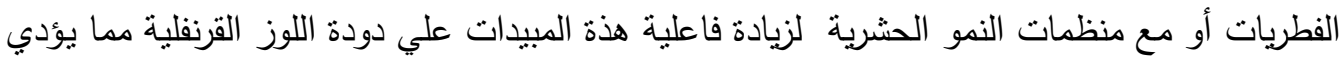
إلي تقليل معدل استخدام هذة المبيدات . 